\title{
A desk review of Sri Lankan migrant worker deaths in 2009
}

\author{
V Jayasuriya ${ }^{1}$, K A K K Wijewardena', T Pathirana ${ }^{1}$ \\ (Index words: migrant worker, death review, foreign employment, Sri Lanka)
}

\begin{abstract}
Objectives A desk review and indirect standardisation techniques are used to describe the mortality risk for Sri Lankan migrant workers.

Methods Annonymised data were extracted from Sri Lanka Bureau of Foreign Employment case files recording deaths during 2009. Indirect standardisation is used to compare death rates taking into account age-sex distribution of the groups. As the actual age death distribution of the departures for 2009 was not available, estimates were derived using departure for 2007, 2008 and 2009.

Results Out of 333 deaths reported in 2009, 328 were analysed. The mortality rates for males and females based on 2007, 2008 and 2009 estimates were consistent for all age groups. Females aged 25-29 years were at an increased risk of death relative to their counterparts in Sri Lanka.

Conclusions Although information from the country of death is inaccessible, data available locally can be analysed systematically to highlight pertinent migrant workers' issues.
\end{abstract}

\section{Ceylon Medical Journal 2012; 57: 120-122}

\section{Introduction}

The number of deaths among Sri Lankan migrant workers has been steadily increasing over the years, however, details of these deaths come mostly from anecdotal communications lacking scientific validity $[1,2$, 3]. This paper based on a desk review using information available at the Sri Lanka Bureau of Foreign Employment (SLBFE) is used to describe the mortality risk for Sri Lankan migrant workers.

\section{Methods}

The SLBFE maintains a case file for each migrant worker containing personal information, and all correspondence received locally. A desk review was conducted using the files recording deaths during 2009. Data were extracted using a pro-forma. No contact was made with any of the families and all data collected were anonymous.

The information obtained was analysed to obtain age-sex distribution of deaths for the year 2009 .
Denominator data for calculation of rates were not directly obtainable from the SLBFE. Although the yearly number of departures by age-sex groups is available the actual age sex distribution of those employed in 2009 is not available $[4,5]$. Therefore estimation was necessary to arrive at a denominator to be used for calculation of standardised mortality rate (SMR). This approximation was based on the observation that most work contracts were of two years duration and a person who died in 2009 was most likely to have migrated within the period $2007-2009[4,5]$. Therefore 3 estimates of SMR were derived based on the age-sex distribution of departures for 2007, 2008 and 2009. Standardised mortality ratios were calculated using the indirect standardisation method based on national age-sex mortality rates for 2007, the latest available rates.

\section{Results}

Out of 333 deaths recorded by the SLBFE during the period of January to December 2009, five files did not record date of death clearly and these were excluded from the analysis. The foregoing discussion is based on 328 deaths recorded during the year 2009 of which 213 (65\%) were of males and $115(35 \%)$ were of females.

All case files were examined for a death certificate and this was available only in $166(52 \%)$ case files (Table 1). Only $56 \%$ of deaths in Kuwait, $50 \%$ in Lebanon and $41 \%$ in Saudi Arabia carried a death certificate.

A question that is asked is whether the migrant workers are at an increased risk of death? In order to answer this question the number of deaths that would have occurred among the departures in each of these years based on Sri Lankan age specific mortality rates (expected deaths) was calculated (Table 2). The actual number of deaths in each age group within 2009 (observed deaths) was compared with expected deaths in 2007, 2008 and 2009 to derive standardised mortality ratios based on departure data of all three years (Table 3 ).

The SMRs for males and females based on 2007, 2008 and 2009 departure show a consistent pattern for all ages. The overall SMR for males and females is less than 100 indicating their risk of death was not more than what it would have been if they were in Sri Lanka. However, The females aged 25-29 years with a SMR of 112.1 (2007 estimate), 103.8 (2008 estimate) and 103.7 (2009 estimate), are at an increased risk of death relative to their counterparts in Sri Lanka.

${ }^{1}$ Department of Community Medicine, Faculty of Medical Sciences, University of Sri Jayewardenepura, Sri Lanka.

Correspondence: VJ, e-mail: <vathsala@sjp.ac.lk>. Received 24 February and revised version accepted 30 May 2012. Competing interests: none declared. 
Table 1. Number of deaths with a death certificate by country of death

\begin{tabular}{lccc}
\hline Country & $\begin{array}{c}\text { Issued death certificate } \\
\text { number }\end{array}$ & $\%$ & $\begin{array}{c}\text { Total number of } \\
\text { deaths reported }\end{array}$ \\
\hline Saudi Arabia & 49 & 41.2 & 119 \\
Kuwait & 33 & 55.9 & 59 \\
United Arab Emirates & 27 & 69.2 & 39 \\
Doha & 26 & 66.7 & 39 \\
Lebanon & 8 & 50.0 & 16 \\
Oman & 5 & 71.4 & 7 \\
Korea & 5 & 71.4 & 7 \\
Jordan & 3 & 37.5 & 8 \\
Bahrain & 1 & 33.3 & 3 \\
Other & 9 & 29.0 & 31 \\
Total & 166 & 50.6 & 328 \\
\hline
\end{tabular}

*Cyprus, Malaysia , Israel, Maldives, Yemen, Rwanda

Table 2. Age and sex distribution of departures, national ASDR/1000 population (2007) and number of expected deaths for 2007, 2008, 2009

\begin{tabular}{|c|c|c|c|c|c|c|c|c|c|c|c|c|c|c|}
\hline \multirow{2}{*}{$\begin{array}{l}\text { Year } \\
\text { Age }\end{array}$} & \multicolumn{2}{|c|}{2007} & \multicolumn{2}{|c|}{2008} & \multicolumn{2}{|c|}{2009} & \multicolumn{2}{|c|}{$\begin{array}{c}\text { National } \\
\text { ASDR/1000 }\end{array}$} & \multicolumn{2}{|c|}{$\begin{array}{c}\text { Expected deaths } \\
\text { in } 2007\end{array}$} & \multicolumn{2}{|c|}{$\begin{array}{c}\text { Expected deaths } \\
\text { in } 2008\end{array}$} & \multicolumn{2}{|c|}{$\begin{array}{c}\text { Expected deaths } \\
\text { in } 2009\end{array}$} \\
\hline & & & & & & & & & & & & & & \\
\hline group & male & female & male & female & male & female & male & female & male & female & male & female & male & female \\
\hline$<19$ & 2803 & 2698 & 2407 & 2648 & 2446 & 2546 & 1.1 & 0.7 & 3.1 & 1.9 & 2.6 & 1.9 & 2.7 & 1.8 \\
\hline $20-24$ & 19022 & 15326 & 22447 & 15008 & 18904 & 14977 & 2.7 & 0.8 & 51.4 & 12.3 & 60.6 & 12.0 & 51.0 & 12.0 \\
\hline $25-29$ & 23916 & 21190 & 33281 & 22885 & 28991 & 22904 & 3.1 & 0.8 & 74.1 & 17.0 & 103.2 & 18.3 & 89.9 & 18.3 \\
\hline $30-34$ & 16327 & 17999 & 24212 & 20986 & 23414 & 23248 & 3.1 & 0.8 & 50.6 & 14.4 & 75.1 & 16.8 & 72.6 & 18.6 \\
\hline $35-39$ & 12224 & 19582 & 17721 & 20505 & 17172 & 21154 & 4.8 & 1.3 & 58.7 & 25.5 & 85.1 & 26.7 & 82.4 & 27.5 \\
\hline $40-44$ & 8675 & 18117 & 12506 & 20513 & 12481 & 21627 & 4.8 & 1.3 & 41.6 & 23.6 & 60.0 & 26.7 & 59.9 & 28.1 \\
\hline $45-49$ & 5890 & 10153 & 9036 & 13390 & 8741 & 14621 & 8.7 & 3 & 51.2 & 30.5 & 78.6 & 40.2 & 76.0 & 43.9 \\
\hline$>50$ & 3889 & 3822 & 6495 & 6273 & 7050 & 6708 & 36.8 & 24.1 & 143.1 & 92.1 & 239.0 & 151.2 & 259.4 & 161.7 \\
\hline Total & 92746 & 108887 & 128105 & 122208 & 119199 & 127785 & - & - & 473.9 & 217.1 & 704.2 & 293.6 & 694.0 & 311.8 \\
\hline
\end{tabular}

Table 3. Age and sex distribution of observed deaths in 2009 and SMR\# estimates based on 2007, 2008 and 2009 departures

\begin{tabular}{|c|c|c|c|c|c|c|c|c|}
\hline \multirow[t]{2}{*}{ Age group } & \multicolumn{2}{|c|}{$\begin{array}{l}\text { Observed deaths } \\
\text { in } 2009\end{array}$} & \multicolumn{2}{|c|}{$\begin{array}{c}\text { SMR } \\
2007 \text { estimate }\end{array}$} & \multicolumn{2}{|c|}{$\begin{array}{c}\text { SMR } \\
2008 \text { estimate }\end{array}$} & \multicolumn{2}{|c|}{$\begin{array}{c}\text { SMR } \\
2009 \text { estimate }\end{array}$} \\
\hline & male & female & male & female & male & female & male & female \\
\hline$<19$ & $0 *$ & 1 & - & 52.9 & - & 53.9 & - & 56.1 \\
\hline $20-24$ & 11 & 7 & 21.4 & 57.1 & 18.1 & 58.3 & 21.6 & 58.4 \\
\hline $25-29$ & 33 & 19 & 44.5 & 112.1 & 32.0 & 103.8 & 36.7 & 103.7 \\
\hline $30-34$ & 27 & 13 & 53.3 & 90.3 & 36.0 & 77.4 & 37.2 & 69.9 \\
\hline $35-39$ & 29 & 24 & 49.4 & 94.3 & 34.1 & 90.0 & 35.2 & 87.3 \\
\hline $40-44$ & 31 & 21 & 74.4 & 89.2 & 51.6 & 78.7 & 51.7 & 74.7 \\
\hline $45-49$ & 31 & 15 & 60.5 & 49.2 & 39.4 & 37.3 & 40.8 & 34.2 \\
\hline$>50$ & 51 & 15 & 35.6 & 16.3 & 21.3 & 9.9 & 19.7 & 9.3 \\
\hline total & 213.0 & 115.0 & 44.9 & 53.0 & 30.2 & 39.2 & 30.7 & 36.9 \\
\hline
\end{tabular}

\#SMR $=$ observed deaths/expected deaths x $100 *$ No observed deaths in group 


\section{Discussion}

This review, based on available information at the SLBFE, is dependent on the recording and reporting of data from different sources and settings. Lack of accurate denominator data was a limitation and three estimates of SMR were derived. Accuracy of these estimates depends on the consistency of age-sex distribution of departures and the duration of work contracts, which was assumed to be 2 years. Assuming both these assumptions to be valid, estimates of SMR describe risks to female migrant workers aged 25-29 years. Although it is not possible to determine the actual risk of mortality from cross sectional data, when considered together with other reports of widespread and frequent harassment of housemaids the possible high risk of mortality for female domestic workers in this age group cannot be dismissed [8-10].

\section{References}

1. Migrant rights. Alarming rates of suicide among migrant workers in Kuwait 2010. Available from: http:// www.migrant-rights.org/ [Accessed 20.08. 2010].

2. Human rights watch. Exported and exposed; abuses against Sri Lankan domestic workers in Saudi Arabia, Kuwait, Lebanon, and the United Arab Emirates. 2007; New York: Human rights watch. Available from: http://www.hrw.org/ sites/default/files/reports/srilanka1107webwcover.pdf. [Accessed 20.08.2010].

3. Priyangika N, Fernando K. Sri Lankan government fails to investigate deaths of migrant workers 2004; World Socialist website. Available from: http://www.wsws.org/ articles/2004/ jan2004/srme-j13.shtml. [Accessed 20.08. 2010].

4. Sri Lanka Bureau of Foreign Employment (SLBFE). Annual Statistical Report of Foreign Employment 2010-2011. Battamulla: Research Division, Sri Lanka Bureau of Foreign Employment.

5. Sri Lanka Bureau of Foreign Employment (SLBFE). Annual Statistical Report of Foreign Employment 2009-2010. Battamulla: Research Division, Sri Lanka Bureau of Foreign Employment.

6. Department of Census and Statistics. Annual Health Statistics, 2007-2009. Colombo: Department of Census and Statistics.

7. World Health Organisation. International Statistical Classification of Diseases and Related Health Problems 2007. 10th Revision. Geneva: World Health Organisation.

8. Perera Y. One in three women migrant workers physically abused. 2011. Survey. Daily Mirror online. Available from: http://www.dailymirror.lk/ news/15533-sr.html. [Accessed 19.12.2011].

9. Dias M, Jayasundere R. Sri Lanka: good practices to prevent women migrant workers from going into exploitative forms of labour. 2002. Working Paper No. 9, Series on Women and Migration. Gender Promotion Programme. Geneva: International Labour Office. Available from: www.ilo.org/ public/libdoc/ilo/2002/102B09_540_engl.pdf. [Accessed 22.08. 2010].

10. Asian Migrant Centre. Asian migrant yearbook. 2005. Available from: http:// asian.station 186.com/ index.php?option $=$ com_frontpage\&Itemid $=1$ [Accessed 18.07.2010]. 